\title{
Individual Stylistic Variability in Independence I Stone Tool Assemblages from Port Refuge, N.W.T.
}

\author{
ROBERT McGHEE
}

\begin{abstract}
Typological comparisons of stone tool assemblages have traditionally been seen as a means of assessing the relationships between components within the Arctic Small Tool tradition (ASTt). Excavation at Independence I components at Port Refuge, Devon Island, allows us to examine this assumption. These components consist of spatially discrete features, most of which appear to be the remains of single family dwellings occupied only once and for a short period of time. It can probably be assumed that the majority of artifacts associated with any feature were manufactured by the individuals who occupied that feature. Marked differences can be seen between feature assemblages in the proficiency with which stone tools were made, and individual stylistic preferences can be postulated on the bases of intra-feature uniformities. If the hypothesis ascribing a great deal of stylistic variability to individual ability and preference is correct, typological comparisons of Canadian ASTt stone tool assemblages may be of relatively little use in judging the relationships between components.
\end{abstract}

RÉSUMÉ. Traditionellement, les types comparatifs des gisements d'outils en pierre se sont revèlés comme un moyen d'apprecier le genre de rapport entre les constituants, cela dans le cadre traditionel des petits outils arctiques.

Les fouilles à site constituants de l'Independence I à Port Refuge, sur l'ile de Devon, nous permettent d'examiner cette hypothèse. Les constituants sont des éléments caracterisitiques discrets sur le terrain; la plupart d'entre apparaissent être des restes d'habitations d'une seule famille, occupées seulement une seule fois et cela pendant une courte periode de temps. On peut supposer que les individus qui occupaient ce site saillant, avaient fabriqué la majorité des artefactes associés à quelque élement important. Des differénces marquées de competence se remarquent entre les assemblages d'élements et la fabrication des outils en pierre et des préferences individuelles dans le style peuvent se supputer, ceal à partir d'une base commune dans les élements saillants. Si l'hypothese, décrivant une grande varieté dans le style, suivant la capacité individuelle et la préférence, est correcte, les comparaisons dans les genres d'assemblages d'outils en pierre Canadiens, peuvent être d'intérêt mineur pour juger des rapports entre les constituants.

Traduit par Alain de Vendegies, Aquitaine Company of Canada Ltd.

\section{INTRODUCTION}

During the past few years there has been increasing archaeological interest in tracing the individual in prehistory, culminating in the recent publication of a book with that title (Hill and Gunn, 1977). Various analytical procedures have been proposed and attempted, ranging from simple extensions of art historical methods to techniques involving machine scanning and complex statistical manipulations. Isolating the work of an individual craftsman appears to be feasible when we are dealing with complex crafts such as basketry or painted ceramics, and indeed archaeologists and art historians have for some time been able to trace the work of individual craftsmen, for example the painters of certain Greek ceramics. 
When we turn to the study of chipped stone tools, however, individual craftsmanship would appear to be much more difficult to detect. Most chipped stone artifacts have far fewer attributes which can be ascribed to style as opposed to function, than do artifacts such as baskets or painted pots. There are complicating factors such as variability in the quality and nature of raw material, which can be expected to be greater in stone than in materials such as wood or clay or paint. We can also expect that there will be a greater amount of individual variability caused by differences in individual motor skills, since stoneknapping would appear to be a skill more difficult to acquire than simple potting or painting.

Although techniques have been demonstrated which may be capable of distinguishing between tools chipped by individual experimental stoneknappers (e.g. Gunn, 1977), it has not been possible to convincingly demonstrate such discrimination in prehistoric materials. Despite the problems listed above, the present paper suggests that it is possible to distinguish between stone tools made by different individuals from a series of Arctic Small Tool tradition (ASTt) components located at Port Refuge in High Arctic Canada. The definition of ASTt follows that of Irving (1964). Making such distinctions allows us to estimate the amount of difference to be expected between tools made by different ASTt flintknappers, and the amount of variability in the work of an individual craftsman. This in turn gives us a better idea of what we mean by a "stone tool assemblage", the basic analytical unit for most comparative studies.

\section{THE PORT REFUGE ASTI COMPONENTS}

Port Refuge is a small bay located on the south coast of Grinnell Peninsula, Devon Island $\left(76^{\circ} 17^{\prime} \mathrm{N}, 94^{\circ} 45^{\prime} \mathrm{W}\right)$, adjacent to a polynia area in Wellington Channel which supports a relatively dense local concentration of sea mammals. On the $10 \mathrm{~km}$ of coastline surrounding this bay we have found evidence of sporadic occupation over the past $\mathbf{4 0 0 0}$ years. The earliest occupations were by ASTt people whose remains have been assigned to the Independence I culture, originally defined in northern Greenland by Eigil Knuth (1967). A total of 136 Independence I features has been located, all on raised gravel beaches at elevations of 20 to $24 \mathrm{~m}$ above present sea level. A few of these features occur in isolation, but most are in groups ranging from three to 31 , spread in roughly linear strings. Each feature is separated from its neighbors by a distance of several meters, and often by several tens of meters. The largest amount of information comes from the Cold component (RbJu-1) located at the northern end of Port Refuge. Here, 31 features are scattered along $200 \mathrm{~m}$ of raised beaches; perhaps half of the features are the remains of dwelling structures, while the remainder represent isolated hearths or outdoor activity areas. Many of the structures appear to be arranged in groups of three or four, and the site appears to represent the accumulated remains of small groups comprising one or a few families who occupied the site sporadically over a period of several years. Judging from the small number of associated artifacts and small amounts of bone refuse, individual occupations appear to have varied from one or a few days to a 
maximum of several weeks; most structures are associated with food remains suggesting an occupation of less than a week. There is no indication that structures were reoccupied by later visitors; if this had been the practice of the time, we should expect to find greater concentrations of refuse in and around the structures. Instead, it appears that each new arrival selected a clean patch of beach on which to set his tent. More detailed description of the Cold component, and of the related Upper Beaches, Cape Hornby, Lake and Whale components, can be found in McGhee (1979).

Each of the dwelling structures on these sites is centred on a hearth surrounded by a box of upright stone slabs, and generally the sides of the hearth have been extended down the length of the structure to form a "midpassage" roughly $50 \mathrm{~cm}$ wide separating the working or sleeping areas on either side of the dwelling. When outlines can be seen, in the form of slight interior depressions or gravel rims, they show that the structures were oval or subrectangular and measured from $2 \times 2.5 \mathrm{~m}$ up to $2.5 \times 3 \mathrm{~m}$. The small size of the structures suggests that they were occupied by single families, or at most by two small families. The midpassage does not appear to separate the living areas of two families, however, but may separate the work areas of men and women. In the 12 structures excavated on the Cold site, artifacts which are generally associated with male activities (weapon points and harpoon endblades for hunting; burins, burin spalls and concave sidescrapers for boneworking; chipping detritus and microblade cores from stoneworking) are strongly associated with the portion of the structure to the right of the midpassage ("right" is defined from a position inside the structure and facing the door on the seaward side). Artifacts associated with the left side of the structure include needles for sewing, and microblades which may have been used primarily in cutting meat and hides, both of which may have been female activities. The distribution by side of house for the 221 burins, burin spalls, weapon points and concave sidescrapers, as against the 112 microblades and needles recovered, is significantly different at the .01 level $\left(x^{2}=6.66\right)$.

The evidence that the two side portions of dwelling structures appear to have been sexually segregated work areas, and not individual family living areas, supports the suggestion that most dwellings were occupied by single families. This leads to an hypothesis that most or all of the stone tools associated with a structure may have been manufactured by a single individual (assuming that stone tools were made by adult men, and leaving aside the probability of some father-son or brother-brother combinations). The relative uniformity in style and manufacturing technique of artifacts associated with most individual structures appears to support this hypothesis, It also gives us some idea of the range of individual variability in the manufacture of artifacts which, when lumped with those made by a number of other individuals, comprise a "site assemblage," one of our basic comparative units.

INDIVIDUAL STONE TOOL ASSEMBLAGES

In examining the stone artifacts associated with individual features, one immediately notes marked differences in the ability or care applied in their 
manufacture. The occupant of Upper Beaches Feature 12, for example, appears to have enjoyed making fine miniature tools from variously coloured cherts (Figs. $2 \mathrm{t}-\mathrm{w}, 4 \mathrm{f}, \mathrm{g}$ ). The man who left a cache of stone tools in front of Upper Beaches Feature 6 was capable of making extremely small and thin endblades, as well as large stemmed points with very even edge serration (Fig. $4 \mathrm{~h}$, i). The occupant of Lake Feature 8, however, appears to have merely selected chert pebbles of an appropriate size and shape, not bothered to remove the cortex, and crudely retouched the working edges to form burins or a graver (Fig. $2 \mathrm{~h}, \mathrm{i}$ ). The occupants of most other features fall somewhere between these extremes, and most appear to have attained at least a basic competence in stoneworking.

The degree of stylistic and manufacturing uniformity existing between artifacts recovered from the same structure is best demonstrated by examining sets of burins recovered from several excavated structures on the Port Refuge sites. Spalled burins are one of the classic and diagnostic elements of all ASTt assemblages. They make up over $25 \%$ of the stone tools, aside from microblades, burin spalls and waste flakes, recovered from the Port Refuge sites, and are the only class of artifact of which several specimens were recovered from many dwelling structures. Since only two to five burins were recovered from each of these structures, statistical techniques for demonstrating uniformity are not useful. We must rely on simple comparison of artifact form and manufacturing technique. The burins discussed are illustrated in Figures 1 and 2, representing most of the specimens recovered in direct association with features which yielded more than one burin.

Cold Feature 1: The three complete burins recovered are not remarkably similar, but all are rather crudely made on thick flakes with little edge retouch and no edge grinding. Two of them have markedly oblique spalls (Fig. $1 \mathrm{a}, \mathrm{b}$ ).

Cold Feature 2: The two complete burins are dissimilar in outline, but are more finely made; the spalls are more vertical than those from Feature 1, there is more extensive edge retouch, and the lateral edges are heavily ground. (Fig. $1 \mathrm{c}, \mathrm{d}$ ). Cold Feature 3: Two of the complete burins from this feature are small and rather shoddily made, obliquely spalled with little edge retouch (Fig. $1 \mathrm{~g}, \mathrm{~h}$ ). The other two are larger, vertically spalled, with more extensive edge retouch (Fig. 1 e, f). All have edge grinding, and all are "left-handed" (that is, the spalled edge is on the right when the artifact is placed on its ventral face), as are two broken specimens from the same feature. Although these specimens vary in size and form, the fact that they are all of the unusual "left-handed" variety suggests that they may have been made by a single individual for different purposes.

Cold Feature 6: Three of the burins associated with this structure were very simply made by selecting a flat flake, shaping it with minimal unifacial edge retouch, and spalling one edge (Fig. $1 \mathrm{i}-\mathrm{k}$ ). Two burins and a concave sidescraper found in the area in front of the structure are all more finely made on dark grey chert, and probably represent the work of a different individual (Figs. 11, 3 a). Cold Feature 7: The three burins found within this structure are small, with fine edge retouch but no edge grinding, with oblique spalls running from a pointed distal end (Fig. $1 \mathrm{~m}-\mathrm{o}$ ). The three burins found in the area in front of the house are larger and more variable (Fig. 1 p-r). One of these (Fig. 1 r) is simply made on a 


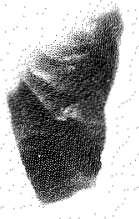

a

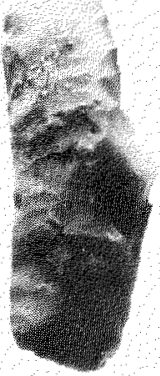

e

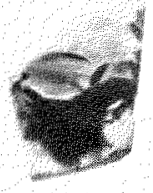

b

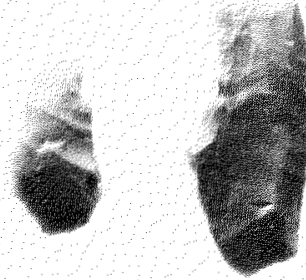

$c$

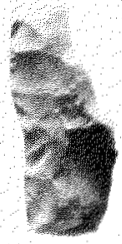



9



in

$d$
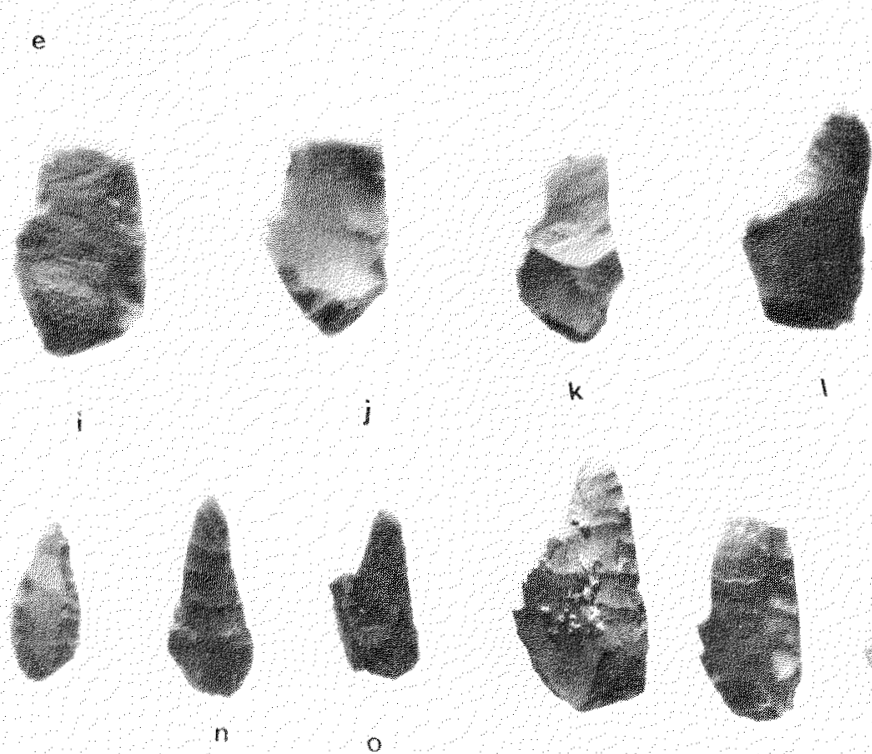



$p$

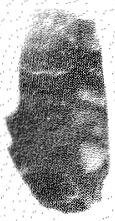

9

FIG. 1. Burins from Cold component: $a$ and b) Feature 1; $c$ and d) Feature 2; e-h) Feature 3; i-k) Feature 6; 1) Feature 6 midden; m-o) Feature 7; p-r) Feature 7 midden. 


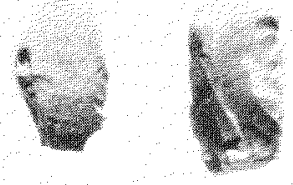

$a$

b
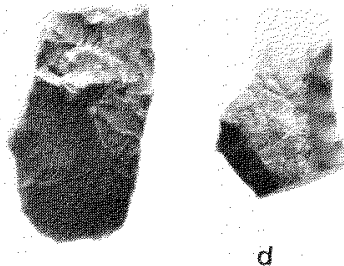

c

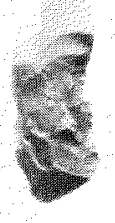

$\mathrm{e}$

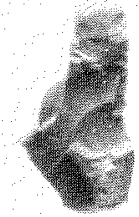

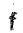

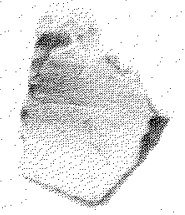

9

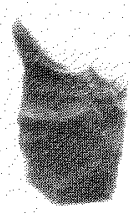

i

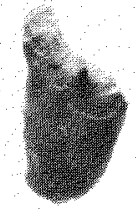

$k$

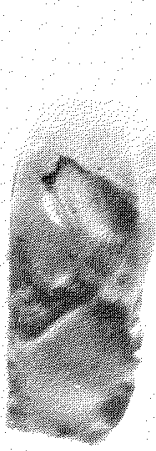

0

$p$

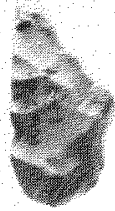

1

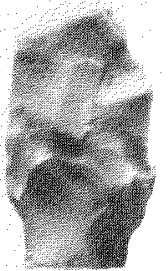

9

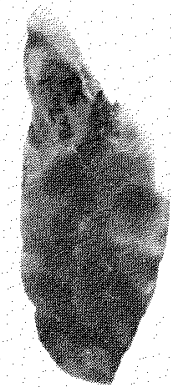

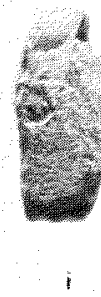

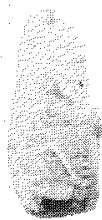

n

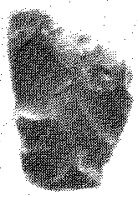

$m$

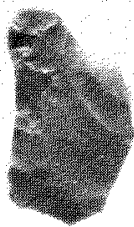

n
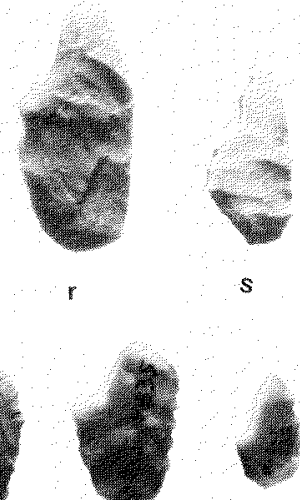

$w$

FIG. 2. Burins from Independence I components: $a$ and b) Cold Feature 9; $c$ and d) Cold Feature 15; e-g) Cold Feature $18 ; \mathrm{h}$ and i) Lake Feature $8 ; j-n$ ) Cold Feature $19 ; 0-s)$ Lake Feature $5 ; t-w)$ Upper
Beaches Feature 12. 
flat flake of light coloured chert, very similar to the burins associated with Feature 6 located $5 \mathrm{~m}$ to the east, and was probably made by the same individual. Cold Feature 9: Both complete burins are made on flat rectangular flakes of beige chert (Fig. 2 a, b). They resemble those associated with Feature 6 but have fine edge retouch, especially on the distal ends.

Cold Feature 15: Both burins recovered are large, finely retouched, with squared distal ends and vertical spalls (Fig. $2 \mathrm{c}$, d).

Cold Feature 18: This small isolated hearth produced four burins of quite variable form. Two (Fig. $2 \mathrm{e}, \mathrm{f}$ ) are long, narrow "right-handed" burins with extensive dorsal surface retouch and extensive edge grinding. One (Fig. $2 \mathrm{~g}$ ) is a crudely made "left-handed" burin made on a flat flake with little edge retouch and no surface retouch. This small camp site or work area may represent the activities of two or more individuals.

Cold Feature 19: All five burins are "left-handed". Three are small and extensively retouched, obliquely spalled from a pointed distal end (Fig. $2 \mathrm{j}-1$ ). The other two (Fig. $2 \mathrm{~m}, \mathrm{n}$ ) are slightly larger but manufactured in the same way; they are made of identical material, and each has been spalled twice, the spalled edge retouched, spalled once again, and the distal end snapped off. All five specimens have edge grinding.

Cold Feature 21: Both burins are finely retouched over the entire dorsal surface, and have fine edge retouch and edge grinding, distal shaving retouch, and are made in the classic ASTt "mitten-shaped" form (Fig. 3 b).

Cold Feature 28: Only one burin was recovered from this feature, but is mentioned because it was associated with a concave sidescraper. Both are made on long and thick flakes of identical chert, with cortex retained on the striking platform on the proximal ends, and both are "left-handed". They appear to have been made by the same individual, perhaps from the same chert nodule (Fig. 3 c).

Lake Feature 5: Five burins were found in association with this feature. Two (Fig. $2 \mathrm{r}, \mathrm{s})$ are small and finely made "right-handed" burins with complete dorsal surface retouch and bifacial edge retouch. The other three (Fig. $2 \mathrm{o}-\mathrm{q}$ ) are very large, made on flakes of light coloured chert, with little edge retouch and no surface retouch. Despite their variability in form, their extremely large size and the fact that they are all "left-handed" suggest that they were made by the same person. This rather diffuse feature may be a work area, representing the activities of two different individuals.

Upper Beaches Feature 12: Six burins were recovered, all made on thin flakes with edge retouch but little surface retouch. All are small and thin, and all have deep edge serration or multiple notching along the edge opposite the burin spall (Fig. $2 \mathrm{t}$-w).

The general uniformity of burins recovered from the same dwelling features supports the hypothesis that each of these sets of artifacts was made by a single individual, probably the man who occupied the dwelling. In less distinctive features, isolated hearths or simply surface scatters of artifacts (Cold Feature 18, Lake Feature 5, the areas downslope from Cold Features 6 and 7), the burins are more variable and there is a suggestion that the activities of two or more 


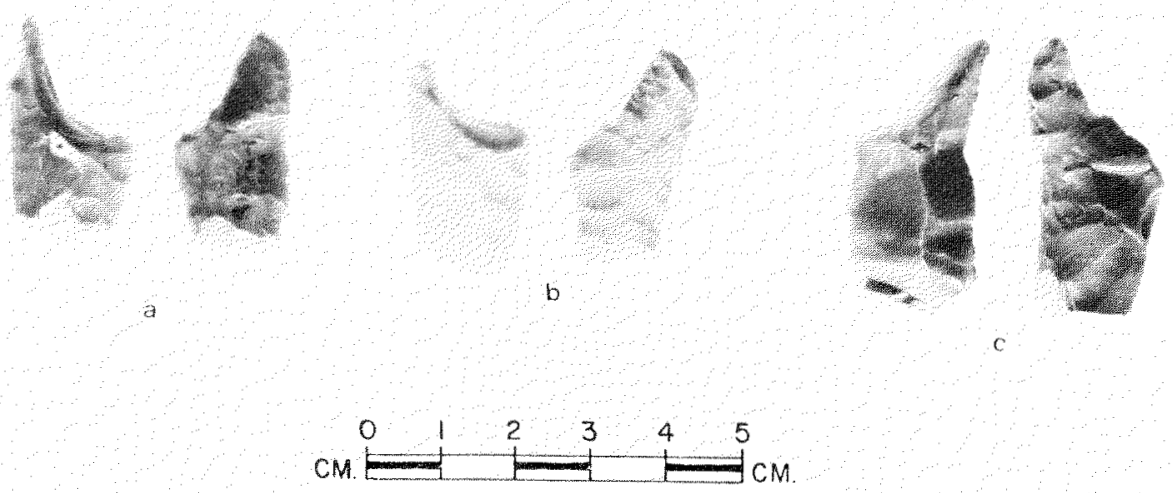

FIG. 3. Burins and associated concave sidescrapers: a) Cold Feature 6; b) Cold Feature 21; c) Cold Feature 28.

individuals are represented. These features may have been outdoor work areas rather than dwellings. The fact that all burins from individual dwelling features are either "right-handed" or "left-handed" also supports the hypothesis of individual craftsmanship. The concept of "handedness" was first applied to burins by Giddings (1964: 218) but, although the proportion of "left-handed" burins in most ASTt assemblages (5\%-20\%) is similar to the proportion of left-handed people in most populations, there was no way of telling whether or not "left-handed" burins were manufactured and used by left-handed ASTt people. Since some of the Port Refuge dwelling features produced only "lefthanded" burins and the remainder only "right-handed" burins, we may now suggest with greater confidence that handedness in burins is in fact associated with the handedness of the manufacturer or user. This is supported by the fact that "left-handed" burins are generally associated with "left-handed" concave sidescrapers, the rare forms on which the working edge is on the left side of the artifact rather than on the right. The distinctive manufacturing techniques seen in burins from individual features can to some extent be seen in other artifacts associated with the same features, primarily in concave sidescrapers. These artifacts resemble unspalled burin blanks, except that the working edge is usually on the right rather than on the left, as in burins; aside from the spalling operation, the two classes of artifacts must have been manufactured in the same way. The similarities between associated burins and concave sidescrapers is illustrated in Figure 3; each set of associated artifacts is similar in size, form, material, flaking technique and, as mentioned before, handedness. This similarity again supports the hypotheses that the artifacts associated with individual dwelling features were manufactured by the individuals who lived in the dwellings.

\section{IMPLICATIONS}

The foregoing section attempted to demonstr ate that certain classes of artifacts, primarily burins and concave sidescrapers, show relative uniformity within individual dwelling feature assemblages. Conversely, there is relatively less 
uniformity in artifact form and manufacturing technique between various dwelling assemblages, suggesting that individual craftsmen made artifacts of the same functional class in somewhat different ways. If this assessment is correct, what are its implications for our interpretations of the Port Refuge ASTt assemblages, or of ASTt assemblages in general?

First, there is no evidence from this study to support Irving's (1964: 326) suggestion that many Alaskan ASTt artifacts were manufactured by stoneknapping specialists who supplied artifacts to the remainder of the population. Rather, the evidence suggests that most if not all of the Port Refuge artifacts were made by each individual for his own use.

As a corollary to this interpretation, if we can recognize the artifacts made by a single individual while occupying a short-term camp, we should theoretically be able to trace that individual archaeologically from camp to camp, and thereby gain insight into the seasonal or life rounds of individual families. Of the $\mathbf{3 0}$ structures excavated at Port Refuge Independence I components, none show sufficient similarities in artifact form to suggest that two or more of these camps were occupied by the same individual. This detracts from my hypothesis that the various dwellings were built and occupied by a relatively small number of

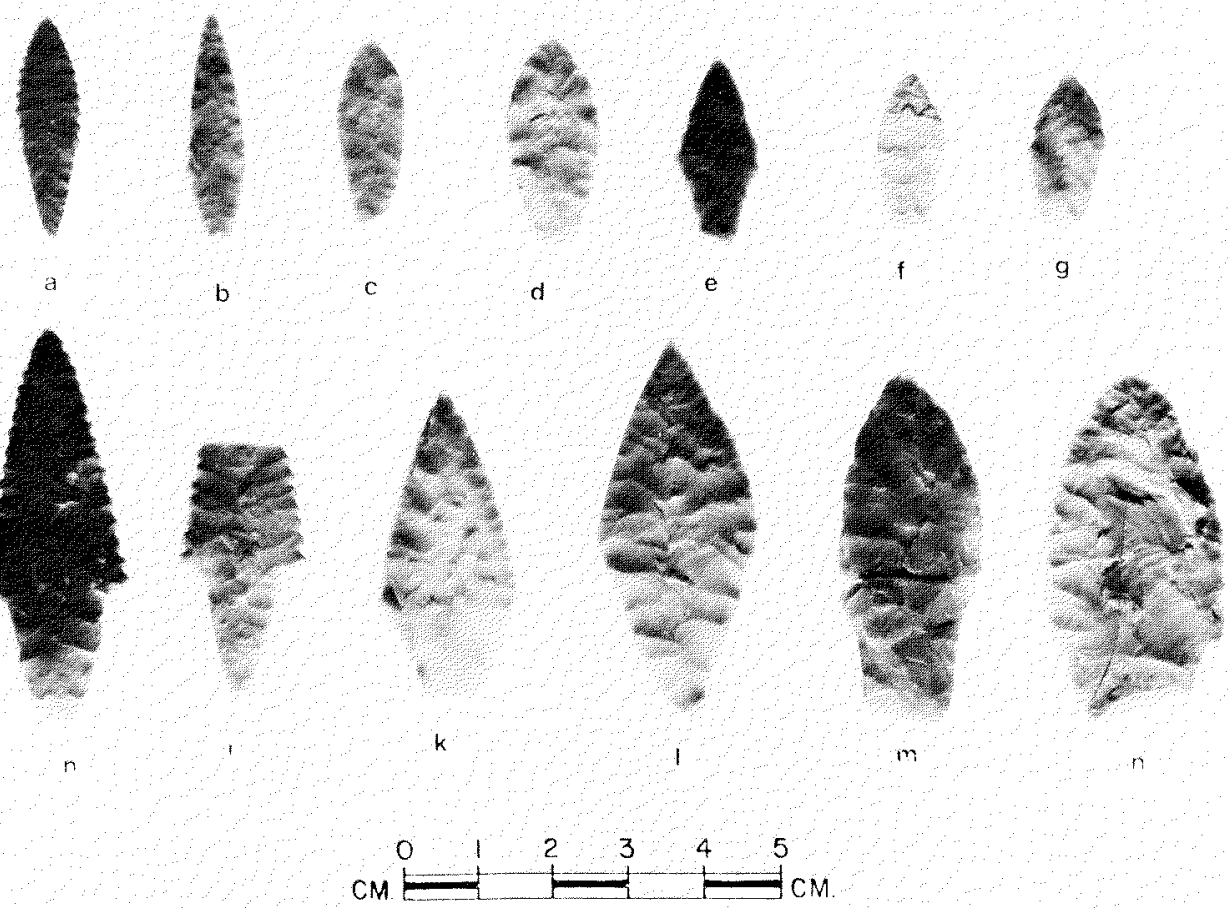

FIG. 4. Stemmed bifaces from Independence I components: a) Upper Beaches Feature 17; b) Cold Feature 3; c) Upper Beaches Feature 6; d) Cape Hornby Feature 11; e) Cold Feature 18; f and g) Upper Beaches Feature 12; h and i) Upper Beaches Feature 6;k) Cold Feature 6; 1) Cold Feature 31; m) Lake Feature 5; n) Cape Hornby Feature 14. 
families who returned to the various sites at sporadic intervals. Rather, it allows the suggestion that population movement in this area may have been more fluid and extensive than previously thought.

On a more general level, these findings have implications for assessing our methods of comparing ASTt assemblages in order to judge the relationships between them. This has been done traditionally either by using specific artifact forms as "markers", or by comparing frequencies of various artifact "types". These methods are based on an assumption that related peoples share sets of ideas as to how artifacts should look and how they should be made. If the above interpretations are correct, the only ideas shared even by people occupying the same component were those related to the functional purpose of the artifact class: overall size, weight, edge angle, and hafting arrangement. Within this set of shared ideas, there appears to have been a great deal of freedom for individual stylistic decisions and individual craftsmanship. This can be illustrated by the class of artifacts from the same ASTt components illustrated in Figure $4 \mathrm{a}-\mathrm{g}$. These "small stemmed bifaces" are all between $25 \mathrm{~mm}$ and $35 \mathrm{~mm}$ in length, all weigh between 0.5 and $1 \mathrm{~g}$, have edge angles of approximately $30^{\circ}$, and are all designed for end-hafting. Aside from two specimens (Fig. $4 \mathrm{f}, \mathrm{t}$ ) which were associated with the same feature, they show a great deal of stylistic variability which can probably be assigned largely or solely to individual stylistic preferences. Similarly, the class of "large stemmed bifaces" (Fig. $4 \mathrm{~h}-\mathrm{n}$ ) appears to have ranged in length between $45 \mathrm{~mm}$ and $50 \mathrm{~mm}$ and weighed between 4 and $5 \mathrm{~g}$; all have edge angles of $40^{\circ}$ to $50^{\circ}$ and all are designed to fit an end-haft. Aside from the two serrated specimens (Fig. $4 \mathrm{~h}$, i) which were found together in a small artifact cache, and which were probably made by the same man, there is again a great deal of variability in the ways in which individuals interpreted this basic functional design. None of these forms are sufficiently uniform to serve as "markers" to characterize the Port Refuge assemblage in comparisons with other ASTt assemblages.

Problems which can arise in comparing artifact type frequencies between assemblages are also illustrated by the burins from the Cold component. For example, $33 \%$ of the burins recovered were "left-handed", whereas in all other known ASTt assemblages the proportion is between roughly 5\% and $20 \%$. The situation at the Cold component is caused by the fact that two of the lefthanders among the artifact makers, those associated with Features 3 and 19, left a relatively large number of burins compared to their right-handed neighbours. When we analyze by feature rather than by artifact number, we find that "left-handed" burins are associated with only $18 \%$ of the features on the site. Similar effects occur in burin attributes such as bifacial retouch or distal shaving retouch.

The major implication of the above analysis is that an "artifact assemblage" is a much more complex thing than we usually consider it to be. It is the sum of a number of individual assemblages, each of which can be very distinctive. Although an individual artifact from an eastern Arctic ASTt assemblage could be "lost" in an Alaskan Denbigh assemblage, as has frequently been stated, we should not be tempted to interpret this as evidence of close or direct relationship, 
but as the coincidental result of two individuals coming across the same interpretations of a basic functional theme within the rather wide possibilities of individual stylistic variability. If we are to attempt to trace consistent forms in artifact styles from one ASTt assemblage to another, at least among those of Arctic Canada, we should probably rely most heavily on those attributes which relate to the introduction of new functional requirements or manufacturing techniques, such as the introduction of a new hafting method, a new technique such as grinding, or a new activity such as bladder-harpoon hunting. In the Port Refuge material at least, stylistic analysis of stone tool forms cannot be expected to tell us much about the relationships between archaeological assemblages.

\section{REFERENCES}

GIDDINGS, J.L. 1964. The archaeplogy of Cape Denbigh. Providence, RI: Brown University Press. $331 \mathrm{pp}$.

GUNN, JOEL. 1977. Idiosyncratic chipping style as a demographic indicator: a proposed application to the South Hills region of Idaho and Utah. In: Hill, James N. and Gunn, Joel (eds.). The Individual in Prehistory, New York: Academic Press. pp. 167-204.

HILL, JAMES N. and GUNN, JOEL (eds.). 1979. The Individual in Prehistory. New York: Academic Press. 258 pp.

IRVING, WILLIAM N. 1964. Punyik Point and the Arctic Small Tool tradition. Ph.D. dissertation, University of Wisconsin. Ann Arbor: University Microfilms.

KNUTH, EIGIL. 1967. Archaeology of the Musk-Ox Way. Ecole pratiques des hautes études. Sorbonne, Contributions du centre d'études arctiques et finno-scandinaves 5, Paris, $70 \mathrm{pp}$.

McGHEE, ROBERT. 1979. The Palaeoeskimo occupations at Port Refuge, High Arctic Canada. Ottawa: Archaeological Survey of Canada Mercury Series, Paper No. 92. 